\title{
THE AFFORDANCES OF TECHNOLOGY IN BUILDING THE ASEAN COMMUNITY THROUGH GRADUATE EDUCATION
}

\author{
Jean A. Saludadez \\ University of the Philippines Open University \\ e-mail: jsaludadez@upou.edu.ph
}

\begin{abstract}
This paper highlights the affordances of technology in building the ASEAN community through graduate education. Specifically, the paper shall focus on the development and the delivery of the ASEAN Studies Graduate Program being offered online by the University of the Philippines Open University (UPOU). The program hopes to develop graduates who can contribute to an enhanced and heightened ASEAN community's consciousness and awareness of its ties of history, culture and bound by a common regional identity but celebrating diversity. The paper shall share the development of the program structure and of the course materials that was accomplished through the collaboration of five open universities in the ASEAN region bound by a philosophy that the commonly shared ASEAN aspiration and dynamics could only be well understood by the ASEAN peoples themselves through a system of knowledge and body of research and repository of data and information on the region in its individual member nations and in its collective character as a regional entity. Further the paper shall share the delivery of the program that is framed by the Open and Distance eLearning or ODeL philosophy characterized by openness, inclusion, resource sharing, access and equity of open learning and learner-centeredness, flexibility, active learning, interactivity, ubiquity, connectivity and constructivism view of e-learning. The paper shall conclude with the challenges of a graduate program within an ODeL framework.
\end{abstract}

Keywords: affordance of technology, ASEAN Studies Graduate Program, UPOU

\section{A Question in the Context of Industrial Revolution 4.0}

In the seminal work of Klaus Schwab (2016) on what the Fourth Industrial Revolution means and how to respond, he highlighted the role of "emerging technology breakthroughs" multiplying unlimited possibilities "of billions of people connected by mobile devices, with unprecedented processing power, storage capacity, and access to knowledge" and the unprecedented outcome such would bring, the "transformation of entire systems of production, management, and governance." Continuing the discussion, Nicholas Davis (2016) reflected on its potential impact on certain areas of concern as identity, voice and community saying:

"the Fourth Industrial Revolution will also affect us as individuals and members of communities. Already, digital media is increasingly becoming the primary driver of our individual and collective framing of society and community, connecting people to individuals and groups in new ways, fostering friendships and creating new interest groups. Furthermore, such connections transcend many traditional boundaries of interaction. 
And asked the question "what do we want these technologies to deliver for us?" This paper is an attempt to answer Davis question in the area of community building through graduate education.

\section{An ASEAN Studies Graduate Program}

The need for a region-wide curriculum on ASEAN Studies to build the foundation for promoting regional cooperation and unity was raised during the 2007 Summit of the Association of South East Asian Nation (ASEAN) Summit in the Philippines. To answer the call to have the teaching of ASEAN studies at all levels, five Open Universities in ASEAN (called OU5), namely, Universitas Terbuka (UT) of Indonesia, Open University Malaysia (OUM), The University of the Philippines Open University (UPOU), Sukhothai Thammathirat Open University (STOU) of Thailand, and Hanoi Open University (HOU) of Vietnam, came together in 2008 to pool their academic expertise to come up with a program that is rooted in the philosophy that the commonly shared ASEAN aspiration and dynamics could only be well understood by the ASEAN peoples themselves through a system of knowledge and body of objective research and repository of data and information on the region in its individual member nations and in its collective character as a regional entity.

In 2010, the five open universities made a consortium agreement to collaborate in developing a framework and course materials for a truly distinctive ASEAN Studies Program at the graduate level with the following specific agreements:

On Program and Course Materials Development

- The Consortium shall jointly write, develop, review and produce the course materials of the Program;

- $\quad$ The course materials developed by the Consortium shall be a common online resource which each member-University is allowed to use, translate, re-use and reform;

- English shall be the medium for course development, appropriate for master's degree level; and

- Participating universities will be permitted to translate, reuse and reform the material and finally, the universities agreed to assist each other in obtaining country-specific materials.

On Program Implementation and Management

- $\quad$ Each member of the Consortium shall offer and manage the Program on their own, consistent with their own academic standards, policies on governance, and operations systems;

- $\quad$ The learning platform of the Program shall be online;

- $\quad$ Cross-enrollment among the students of the Consortium shall be allowed, in accordance with the respective rules and policies on enrollment of concerned universities;

- Engagement of faculty/tutors from any member of the Consortium shall be allowed subject to the existing policies of the requesting consortium members; and

- Marketing and promotions efforts for the Program shall be handled by the members of the Consortium individually and collectively.

\section{On Financial Considerations}

- The cost for course materials development and related expenses assigned to each of the member-Universities concerned shall be in accordance with the Summary of Agreements at the UPOU Meeting of 2009;

- $\quad$ Each member of the Consortium shall charge its standard fees for tuition and other fees to its own students; and

- The Consortium agrees to waive all special fees for cross-registration of students. 


\section{The ASEAN Studies Graduate Program at the UP Open University}

Drawing from the basic framework of the OU5, the UPOU has offered the ASEAN Studies Graduate Program as a conjoint program (having Graduate Certificate and Master's Degree) designed 1) to promote regional and global understanding about ASEAN countries from the perspective of ASEAN; increase the ASEAN community's consciousness of its common historical, cultural, and regional identity; and obtain a balanced perspective in ASEAN studies and 2) for those who will have strong interest and influence on ASEAN-related affairs such as public servants, diplomats, educators, businessmen, and those involved in non-government organizations and the like.

The University of the Philippines Open University (UPOU) offers the ASEAN Studies Graduate Program within the Open and Distance eLearning (ODeL) framework that draws from the philosophy of openness, inclusion, resource sharing, access and equity of open learning; of learnercenteredness, flexibility, and active learning, of distance education; and of interactivity, ubiquity, connectivity and constructivism of e-learning. In other words, UPOU accomplishes its educational goals through the affordances of digital technology. As Alfonso (2014) explicated:

These affordances and features are infused with values that underpin the university-- excellence academic freedom, humanism, intellectual pluralism, democracy, and service to society. This ethos creates the spirit of the university. Together, all these elements are embedded and facilitated by networked information and communication technologies and make up Open and Distance eLearning. The interweaving of these components can bring about social transformation by producing learners who have the ability to seek new information from different sources, translate this information into applicable knowledge, communicate this knowledge in various forms and situations, and work in different cultural contexts.

The UPOU started offering the program in 2014 and currently, this Academic Year 20182019, the program has more than 300 students scattered around the region. The following tables show the distribution of students per degree academic year (Table 1), gender per degree (Tables $2 a$ and 2b), employment (Table 3), profession (Table 4) and location (Table 5).

Table 1. Distribution Of Students According To Degree Per Academic Year $(n=370)$

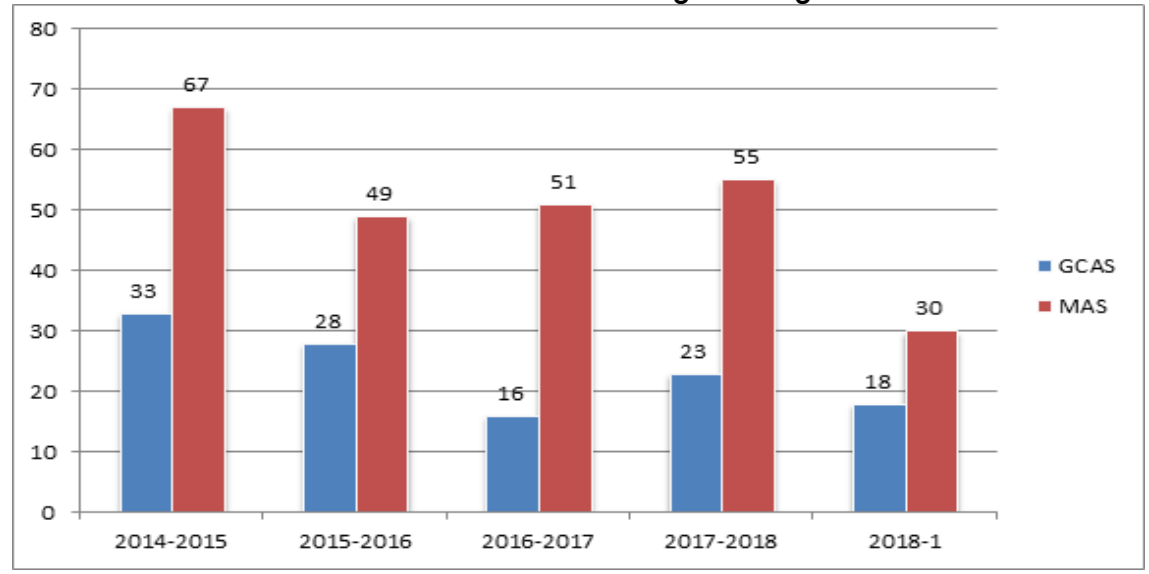


Table 2a. Distribution Of Students According To Gender Per Academic Year In The Graduate Certificate $(n=120)$

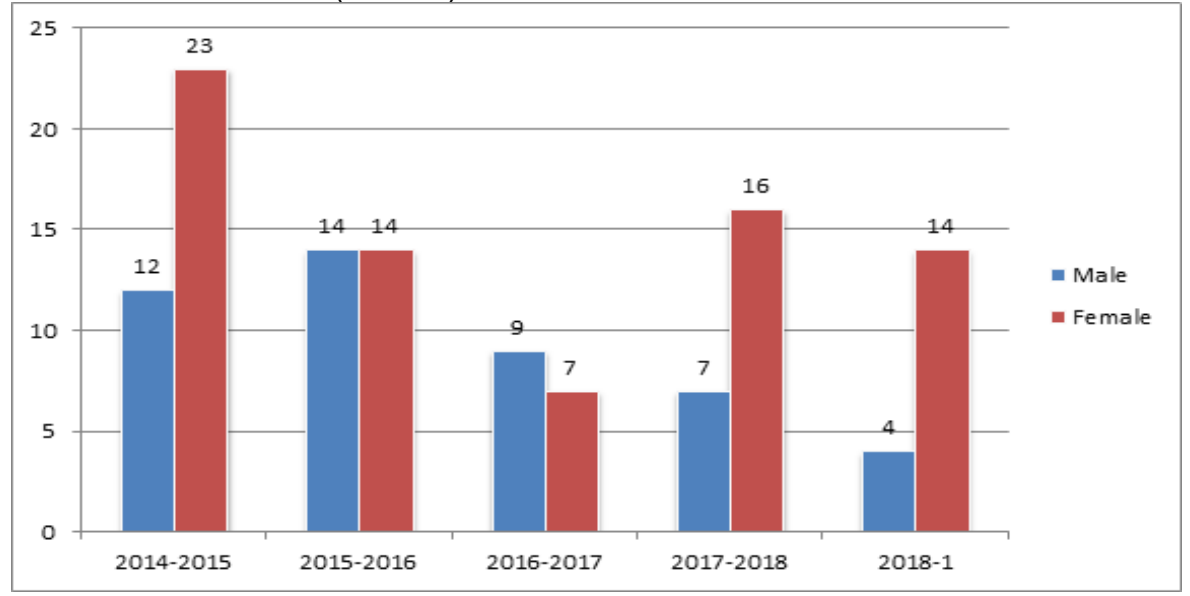

Table 2b. Distribution Of Students According To Gender Per Academic Year In The Graduate Certificate $(n=120)$

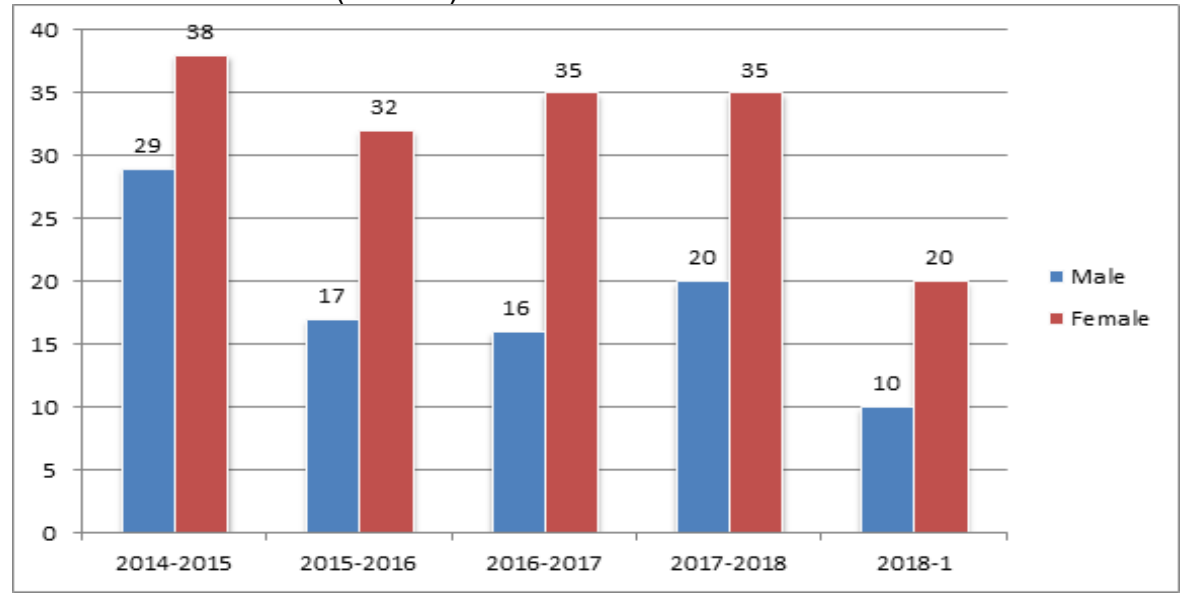

Table 3. Distribution Of Students According To Employment ( $n=370)$

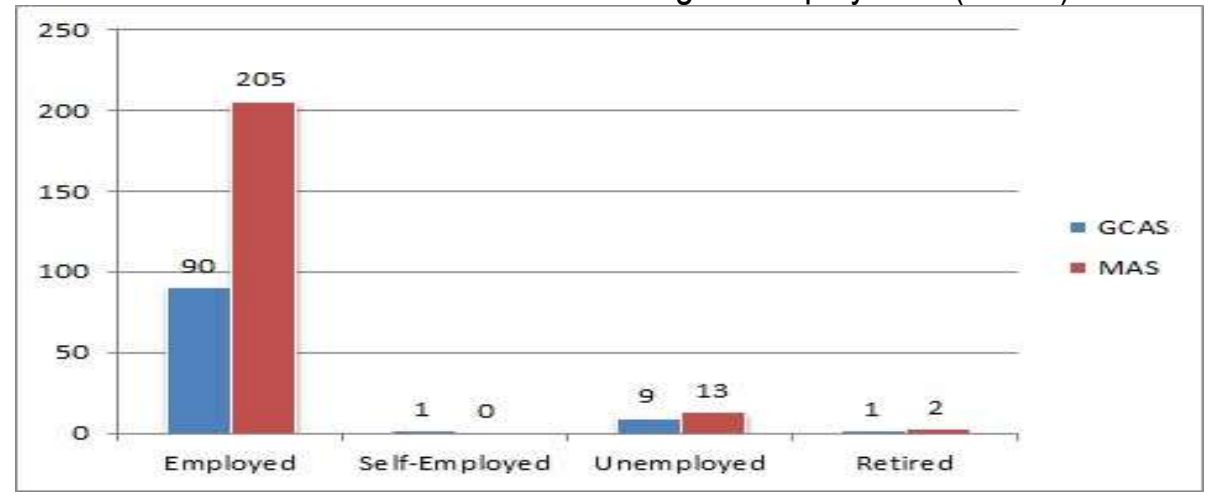


Table 4. Distribution Of Students According To Profession ( $n=370)$

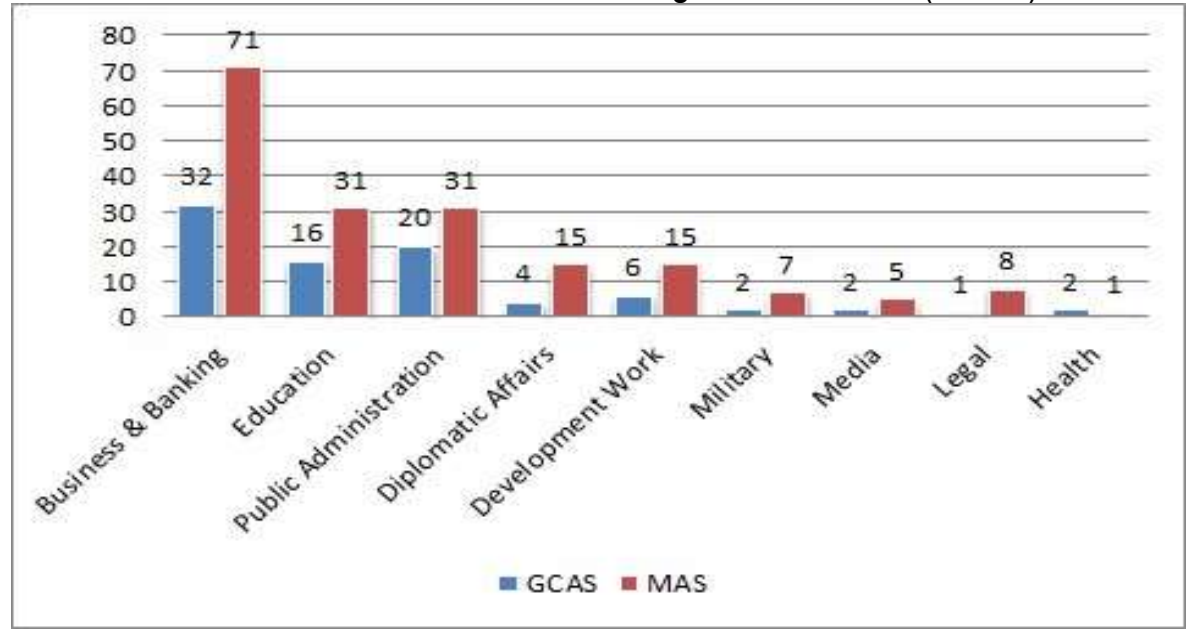

Table 5. Distribution Of Students According To Location Per Academic Year ( $\mathrm{n}=370)$

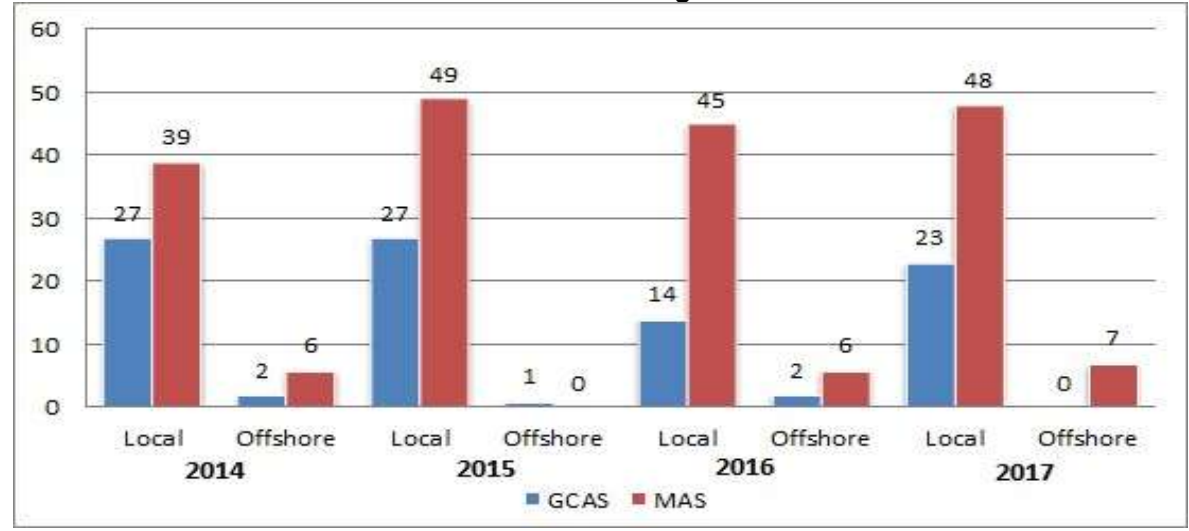

The faculty complement of the program mainly come from the various campuses of the University of the Philippines System and from other academic institutions in the country and in the consortium member universities in the region, some of them are on retirement status.

\section{Affordances of Technology}

What has the digital technology delivered for us? Looking at the above data and reflecting on our experience offering the program for four years, the affordances of technology in building the ASEAN community through graduate education come in several forms:

\section{Collaboration in Teaching}

The UPOU's learning management system (LMS) called MOODLE has enabled the teaching of the courses regardless of where the faculty is located. Further, because the LMS platform allows repository of course materials produced by academics beyond the confines of the physical university, it can be said that collaborative mentoring is also enabled by the technology. Co-creation of Text and Knowledge

The LMS platform enables free sharing of ideas and participation of the students in the creation of knowledge. One course, for instance, ASEAN 222 (Art in the ASEAN Region) requires the 
students who are in the different parts of the world to document through ASEAN nationalities as they share their thoughts with others their perceptions of their own art forms and cultures. In this way learners experience the process of co-creation of academic texts with co-learners, teachers, and individuals from their communities.

\section{Coming Up of a Community of Learners}

The ubiquity of the technology afforded people coming from different walks of life to be part of a community of learners. As can be seen in the tables above online education enables the inclusion of and provides equal opportunities for all ages and places, gender and employment/work groups. The technology enables transcendence of distance and the offering of opportunities to those who are unable to attend classes or who do not have access to residential educational institutions but have the facility for internet connection. They may be working overseas or on the move or housebased as reflected in the following excerpts from the admission application essays in the first year of the program's offering:

My main purpose for applying to distance education program is to pursue and obtain a graduate degree without leaving or sacrificing my work overseas. (Overseas Worker).

With my current status of always being mobile as an advocate, a distance education program is highly favorable to suit up my needs as well. (Mobile Worker).

Distance learning appeals to me because my daughter is still in her preschool years and I want to be effective in my roles as an educator, a graduate student, and a mother/spouse. (House-based Worker).

\section{ASEAN Studies Graduate Program of the Future}

What else do we want these technologies to deliver for us?

The Program has embarked on a research and development project aimed at developing a non-human proctored assessment system platform. The ASEAN Studies Online Assessment Platform (OAP) is a unified system integrating web information system for encoding, verifying and checking exams and stand-alone/client program for taking an exam securely with a non-human proctor. The platform shall be developed further for just-in-time communicability with the users, enhanced ability for examinee authentication and greater capacity for detection of possible cheating.

The program hopes that such move would help widen the circles of students who can enroll in the program and would further contribute to the accomplishment of the program goals.

\section{REFERENCES}

Alfonso, G. J., Jeotee, K., Lumanta, M.F. \& Saludadez, J. A. (2014). Towards an Assessment System for ODeL: The Case of ASEAN Studies Graduate Program of UP Open University". Paper presented at the International Conference on Ubiquitous Learning, Shanghai, China, 1-2 May 2014.

Davis, N. (2016). What is the Fourth Industrial Revolution. 
https://www.weforum.org/agenda/2016/01/the-fourth-industrial-revolution-what-it-means-andhow-torespond/Retrieved 2018-10-20.

https://www.weforum.org/agenda/2016/01/what-is-the-fourth-industrial-revolution/Retrieved 2018$10-20$.

Schwab, K. (2016). The Fourth Industrial Revolution: what it means and how to respond. 